\title{
Management of geomechanical processes - the basis for selecting the optimal technologies for the development of mineral deposits
}

\author{
Anatolii Kozyrev ${ }^{1}$, Iuliia Fedotova ${ }^{1}$, and Eduard Kasparyan ${ }^{1}$ \\ ${ }^{1}$ Mining Institute KSC RAS, Lab. of Geomechanics, Apatity, Russia
}

\begin{abstract}
Annotation. When carrying out mining operations, a rock massif responds to technological impacts in the form of developing strains and fractures. Under certain conditions, this response occurs as dynamic and gas dynamic destructions of rocks with intensive release of energy, which creates threats to security and disrupts a working technology. To substantiate the optimal mining technology, which would be maximum adequate to the specific geological and geomechanical conditions of a deposit development, it is necessary to organize a comprehensive monitoring of geomechanical processes in rock massifs. The paper considers general principles to organize the geomechanical monitoring under conditions of the hierarchically-blocked rock massifs in the gravitational-tectonic field of the natural stress state. The authors give main recommendations for managing geomechanical processes in the rock mass for various mining methods.
\end{abstract}

\section{Introduction}

When carrying out mining operations, a rock massif responds to technological impacts in the form of developing strains and fractures. Under certain conditions, this response occurs as dynamic and gas dynamic destructions of rocks with intensive release of energy, which creates threats for security and disrupts a working technology. The only way to overcome the dangerous increase of accidents' frequency during mineral deposits mining is to increase the level of knowledge about processes and events in mining operations and on this basis to develop rules and techniques that ensure their effectiveness and safety.

The rock massifs form special physical media, the state of which is determined by three components: rock properties, structural features and natural stress state. Since for all these components the degree of heterogeneity is high enough, in general for rock massifs the heterogeneity is substantially higher than for any other artificial or even natural materials [1]. The significant heterogeneity of the rock massifs determines the extremely wide variability of rock characteristics and makes it necessary to apply specific methods to study the properties and patterns of their variation, depending on the considered volumes, regimes of force impacts, the time of impact, etc. [2]. A characteristic feature of mineral deposits is an extremely wide variety of mining and geological conditions, which makes each mine or

* Corresponding author: fjulia@,mail.ru 
open pit (or their various parts) unique both in the form of ore bodies developed and in mining methods. From there, the management of geomechanical processes in the rock mass implies a purposeful regulation of the nature and parameters of the processes. In this case, the researchers strive to achieve the development of processes in a desired safe direction, and to keep their parameters within predetermined safety values. To do this, in some cases engineering solutions are used to reduce the stress concentrations in the elements of the mining methods; in others it is necessary, on the contrary, to increase the concentration of stresses and create conditions for the destruction of rocks in some areas of the rock mass. The geomechanical processes management also includes the measures to target changes in the properties of the rock mass, both to improve its stability and effectively destroy the rock mass.

For each deposit the monitoring systems, as well as the methods of controlling geomechanical processes, have their own specifics [2-6]. At that, knowledge of the patterns of changes in these processes, depending on the influencing factors, allows not only predicting the development of negative events and developing the measures to ensure the efficiency and safety of mining operations, but also, with due regard for them, choosing the optimal mining techniques to reduce the cost of prevention and the elimination of the consequences of accidents.

\section{The organization of integrated monitoring}

Monitoring of changes in rock mass parameters is an integral part of modern subsoil use. It is organized for mining provinces to obtain the necessary information for the development of measures to ensure the safety of mining operations and any facilities, both underground and on the surface [7-11].

Since mining-engineering systems in general are integrated multicomponent structures, the organization of geomechanical monitoring in them should be based on systemic principles that reflect the change in the state in space and time of the rock mass and various engineering facilities built during the construction or the exploitation of deposits.

Taking into account the general regularity of the hierarchically-blocked structure of the rock mass from the point of view of the scale of strains and destructions, it is possible to identify regional and local levels of geomechanical processes and, accordingly, regional and local monitoring of geomechanical processes is needed. At that, the development of geomechanical monitoring systems should include the following provisions [12]:

- the structure of geomechanical monitoring should be multicomponent and multilevel (hierarchical) and should correspond to the structural features of the monitored rock mass (the entire hierarchy of its constituent blocks), geomechanical zoning results, and classes of controlled objects;

- geomechanical monitoring should be integrated with the use of different observation methods in accordance with the features of controlled objects;

- the structure of geomechanical monitoring should be optimized in terms of economic and technical costs for its organization;

- a unified geomechanical monitoring system should be open and allow for painless connection of newly emerging control objects and application of new observation methods. Based on the experience of performing geomechanical monitoring at various mining enterprises of the Kola Peninsula, a single integrated system for geomechanical monitoring of rock mass is represented as a network of testing sites consisting of separate observation points located both on the day surface and in underground excavations [12]. Moreover, the observation points are laid within the limits of the mining areas in such a way that their minimum number within each controlled boundary of the structural blocks is not less than two. If possible, the observation points are also constructed directly into the structural 
heterogeneities, which are the boundaries of the structural blocks. Hence it follows that the minimum number of points on each edge of the structural block must be four. The total number of observation points in the monitoring system can reach several tens [12].

On the daily surface, it is reasonable to use geodetic and seismic observations and, consequently, to develop networks of observation points of two types over the entire area of the deposits. In underground conditions it is reasonable to organize three kinds of observations: inclined-deformometric, seismic and geodetic, and, accordingly, to develop three types of monitoring networks for the rock mass state at different levels of structural blocks [12].

Also, within the rock mass blocks indicated on the basis of geomechanical zoning, it is necessary to measure the parameters of the operating stress fields using direct or indirect methods.

It is very important that all observational networks and testing sites to be strictly interconnected by applying a single coordinate system, agreed time frames for measuring cycles and methodologically uniform methods of processing the information received.

\section{Creation of geomechanical models}

The analysis of the monitoring data provides for the indispensable development of a general model of the rock mass, containing a developed (planned to develop) deposit and the monitored processes. The models are determined by the degree of detail of the available information for the rock mass and the processes under consideration. However, even in the case of a clearly insufficient amount of information, the models, even primitive ones, should be developed, otherwise monitoring becomes unproductive [13].

The next stage of the model design is the compilation of particular geomechanical models of separate earlier identified areas of the rock mass. In this case, an actual mining and engineering situation is superimposed on an engineering-geological model and all changes in the natural state of the rock mass, caused by mining at a certain time, are recorded.

During monitoring, the level of knowledge about an object of observation is increased, and as a result, models are usually complicated and their adequacy to the really developing processes in the rock mass is increased.

\section{Management of geomechanical processes}

From the point of view of geomechanics, there are no great differences in the development of geomechanical processes, both in the construction and operation of underground and surface structures. This makes it possible to apply uniform methodological approaches to ensuring safety and solving geomechanical problems in mining operations by both open and underground methods [13].

\subsection{Open-pit mining operations}

The only but very significant feature of rock mass in open mining operations is a very high proportion of near-surface, mostly weak rock layers, often representing a soil mass. In the soil mass, stratification is most often found from structural heterogeneities, and the stressed state is caused exclusively by the gravitational field. To a certain extent, the same applies to dump mass, which also represents actually artificial bulk soils, but, unlike typical soils, it has significant heterogeneities in the fractional composition. 
As the depth of mining increases, the proportion of soil masses decreases; the marked features for open pits lose their significance and rock mass, from the geomechanical point of view, becomes more and more identical to the rock mass with which miners deal during the construction of underground structures and mining enterprises. For dumps, these features remain, and they have to be taken into account when solving geomechanical problems.

Technological parameters of open mining operations are largely determined by the development of geomechanical processes (strains, displacements and fractures) in the rock mass of the deposits being developed. At that, the main geomechanical problems in open mining are to ensure the slope stability and stability of benches and dumps.

Based on the very long service life of the open pit walls, especially in the upper benches, the open pit walls are almost analogous to the capital excavations of underground structures, in terms of the development of geomechanical processes. Therefore the methods of ensuring their stability can be carried out in analogous methods - either by regulating (usually decreasing) acting stresses in the contour rock mass, or by a purposeful change in the properties of the rocks composing the benches and walls.

Thus, the management of geomechanical processes in open-pit mining is to justify the optimal structures of the open pit walls, in terms of view of safety and efficiency, to determine the angles of slopes and the height of the benches, parameters of the safety and transport berms, as well as the angles of slopes and the height of the dumps.

\subsection{Underground mining operations}

Geomechanical processes in the rock mass during capital and preparatory excavations are developed in various ways depending on the geological conditions, i.e., all the determining factors: properties, structural features and natural stress state of the rock massif, as well as shapes of sections and sizes of underground excavations. Based on this, the management of geomechanical processes during driving of the excavations is carried out by choosing the optimal shapes and sizes of the cross sections of the excavations, their optimal orientation relative to the natural stress field of the rock mass and the prevailing systems of structural heterogeneities, and also by choosing sustainability measures and, in particular, necessary types of supports and the calculation of their parameters. For the room mining methods, the stability of the pillars and the roof of the rooms must be maintained for the set time. For the backfilling mining methods, the strength of the material-filler and the permissible deformations of the covering rocks should be ensured. For the caving mining methods, the stability of the covering rocks must be initially ensured, and then their collapse with specified parameters.

Depending on the strain and strength characteristics of the rocks directly adjacent to an excavation's contour, the rocks on the contour of excavations can be deformed or destructed. Due to the high velocity of deformation (approaching the velocity of sound), elastic deformations around the excavation's face have time to develop before the construction of the support, and as a result often go unnoticed. At the same time, the previously driven parts of the excavation, if they are fixed with very rigid support, can be exposed to huge destructions caused by additional, even insignificant, elastic deformations. To avoid this, rigid permanent supports are always constructed with some delay from the face. At that, it is important to emphasize that this lag of the permanent support must be carried out not only for the purpose of protecting it from the effects of blasting operations, if drilling is performed by drilling and blasting (a very common opinion), but also from the indicated effect of elastic deformations. In fact, the choice and justification of the lag of the permanent support installation from the face is an element in the management of geomechanical processes in the near-boundary rock mass. 
Thus, the safety and efficiency of underground mining will be ensured only in a case of correct choice of methods controlling the state of the surrounding rock mass, when the stresses and deformations arising therein do not exceed the permissible values.

\subsection{Combined mining}

Combined (open and underground) mining is an independent mining system of extracting minerals within a single deposit with its inherent features, advantages and disadvantages. The principles of spatial and temporal combination of open and underground developments within a single field are used as a basis for distinguishing individual varieties of combined mining methods. It is assumed that the main feature of the space-time combination of open and underground mining operations is their carrying out in zones of mutual geomechanical influence.

During open mining in the collapse zones, the most dangerous form of deformation of the undermined rock mass is funnelling. A decisive moment is the moment when the caving funnels come to the surface. In this connection it is necessary to carry out underground mining operations under the bottom and in the open pit walls according to schemes and parameters that would ensure minimum conditions for the formation of caving funnels. But if the caving funneling cannot be avoided, then during combined mining of the deposit, the obligatory condition of underground operations is to ensure the exit of a caving funnel to the surface in the shortest possible time.

Experience shows that the formation of voids, hanging and funnels is largely determined by a mining method. So the probability of funneling increases with a one-stage ore block breaking in the clamp in comparison with a two-stage block breaking into the compensation space. This is explained by lower values of the soil conversion factor (1.061.26) against (1.35-1.4) with a two-stage breaking. Another important condition, which also makes it possible to significantly reduce the funnel formation in the collapsed rock mass, is the uniform release of the broken ore in the area of the blocks. The most convenient is the simultaneous uniform release of broken ore from all the blocks that undermine a part of the open pit.

However, for geological and other objective reasons, it is not always possible to implement the above recommendation. Therefore, in each specific case it is necessary to choose such a scheme for working out the blocks and releasing the ore, which would ensure the most uniform movement of the collapsed rock mass. For example, for conditions of steeply-inclined deposits, it is recommended to maintain a uniformly sequential order of ore release from as many holes as possible, with a minimum distance between them and small doses of release. At that, the velocity of release should be of the order of $4-5 \mathrm{t} / \mathrm{m}^{2}$ per day. It is reasonable to start the release from the footwall of the ore deposit (at large reservoir thickness), and in the direction of strike the "ore - rock" contact should be kept flat, with an angle of inclination to the horizon of the order of $50^{\circ}$. In other conditions, optimal schemes and production modes may be different.

\section{Conclusions}

The organization of a single system for the integrated monitoring of geomechanical processes in rock massifs during the development of mineral deposits should be aimed at monitoring the state of different-scale faults. The analysis of the obtained data will allow predicting the development of changes in the state of the hierarchically-blocked environment based on the created multi-scale geomechanical models, taking into account specific mining and geological conditions in the gravitational-tectonic natural stress state field. 
General recommendations for managing the geomechanical processes in rock massifs when using various mining methods require the detailed consideration, taking into account the specifics of concrete deposits. It should be noted that the management of the geomechanical processes is the basis for the justification of the optimal mining technology.

\section{References}

1. M.V. Rats, Heterogeneity of rocks and their physical properties. M., Nauka (1958).

2. Methods and systems of seismic deformation monitoring for mining-induced earthquakes and rockbursts. Integration projects of SB RAS, Novosibirsk: SB RAS, 24 (1). (2009).

3. B.V. Vlasenko, V.P. Potapov, V.A. Fedorin, Mining physical-engineering monitoring. Mining physical-engineering bulletin, 10, 108-113. (2001).

4. V.A. Il'ichev, P.A. Konovalov, N.S. Nikiforova Particularities of geomonitoring when constructing underground facilities, Foundations, basis and mechanics of soils, 4, 2026. (1999).

5. Yu.S. Isaev, S.N. Mulev, Experience in creation of geodynamic monitoring systems in mining enterprises, Mining Journal, 10, 22-24. (1999).

6. E.V. Kasparian, A.V. Kozhukhovskii, I.Yu. Rozanov, Experience in organization of monitoring of slope stability, Mining Journal, Izvestia VUZov, 5, 67-74. (2015).

7. A. Kozyrev, V. Panin, Iu. Fedotova, Mining-Induced Seismicity in the Kola Peninsula Mines. Journ. of Civil Eng. and Arch., ISSN 1934-7359, USA. Volume 7, 7 (68), $897-$ 906. (2013).

8. S. Cesca \& all, MINE, Mining Environments: continuous monitoring and simultaneous inversion, Geotechnologien science Report, Vol.18, 3-13. (2011).

9. C. I. Trifu, F. T. Suorineni, Use of microseismic monitoring for rockburst management at Vale Inco mines, Controlling Seismic Hazard and Sustainable Development of Deep Mines. C. Tang (ed.), Rinton Press, NY, 1101-1114. (2009).

10. G. Nosenzo, B. E. Whelan, M. Brunton, D. Kay and H. Buys, Continuous Monitoring of Mining Induced Strain in a Road Pavement Using Fiber Bragg Grating Sensors, Photonic Sensors Vol. 3, 2, 144-158. (2013).

11. T. Urbancic, C. Trifu, Seismic Monitoring of Mine Environments, Mapping and Monitoring the Mine Environment, Proceedings of Exploration 97: Fourth Decennial International Conference on Mineral Exploration, A.G. Gubins (ed.), 941-950. (1997).

12. A. A. Kozyrev, E. V. Kasparian, Iu. V. Fedotova, Monitoring of natural and mininginduced processes during mining operations in highly-stressed rock massifs, Monograph, LAP Lambert Academic Publishing RU, Saarbrucken, Deutschland $161 \mathrm{p}$. (2016). ISBN 978-3-659-97138-9

13. A.A. Kozyrev, V.I. Panin, I.E. Semenova, Yu.V. Fedorova, V.V. Rybin, Geomechanical support of engineering solutions in mining in highly-stressed rock massifs. Physical-engineering problems of minerals development, SB RAS, 2, 46-55. (2012). 